\title{
Cancer cell metabolism resulting in multidrug resistance to chemotherapy and possible ways out
}

\begin{abstract}
Cancer has posed a great challenge to its victims all over the world. Researchers have developed several measures to combat this problem. However, it has been discovered that the major hindrance to breakthrough in this field is that cancer cells are able to resist treatment. A large pool of information was retrieved from several reputable articles most especially the recently published ones. In this review, some of the mechanisms adopted by these cells to confer resistance to treatment will be discussed. These mechanisms include drug efflux via $\mathrm{ABC}$ transporters, deregulation of cell death mechanisms, modification of drug targets and repair of damaged DNA. The possible means to overcome this resistance are also reviewed.
\end{abstract}

Volume II Issue 3 - 2020

\author{
Oluwaseun Fapohunda, Damilola Comfort \\ Ajayi \\ Department of Biochemistry, Adekunle Ajasin University, Nigeria
}

Correspondence: Oluwaseun Fapohunda, Department of Biochemistry, Adekunle Ajasin University,Akungba Akoko, PMB 00I, Nigeria, Tel +2347062998896,

Email oluwaseun.fapohunda@aaua.edu.ng

Received: May 24, 2020 | Published: June 22, 2020

\section{Introduction}

Reports have shown that cancer is a serious menace to human life and health., ${ }^{1,2}$ Over the years, it has become a global threat to the human race. Cancer, a group of diseases which is a serious challenge to humans, is usually characterized by uncontrolled cell growth, morphological and cellular transformation, angiogenesis, deregulation of apoptosis, metastasis, abnormal growth or division of cells (neoplasia). ${ }^{3-6}$ A collection of cancer cells is often referred to as a "tumor" and the terms "tumor" and "cancer" may be used interchangeably. ${ }^{7}$ Globally, asides cardiovascular diseases, a high mortality rate can also be attributed to cancer (WHO, 2018). Based on a study by Globocan-2018, it was reported that there were 18.1 million new cancer cases and 9.6 million cancer deaths in $2018 .{ }^{8}$ Deaths associated to cancer increased by about $17 \%$ in comparison to data available in 2012. Lung cancer is reported to be prevalent among males, while breast cancer is the most common in females. ${ }^{9}$ It is expected that the number of new cases will reach 23.6 million by $2030 .^{1,2}$ Cancer therapies that has been adopted include: surgery, radiotherapy and chemotherapy which is the most common. ${ }^{2,10}$

Lately, even though chemotherapy drugs have been effective in treating cancer patients, multidrug resistance to drugs by these cancer cells has posed a great challenge., ${ }^{2,1-14}$ Cancer cells develop measures which enable them to inhibit drugs thereby reducing the drug's effectiveness. The potency of chemotherapy drugs, which has been limited by multidrug resistance, is a major threat in the treatment of cancer. ${ }^{15,16}$ Generally, drug resistance can either be endogenous (intrinsic) drug resistance or acquired drug resistance. ${ }^{2,17,18}$

Different mechanisms of multidrug resistance (MDR) which include dysregulation of drugs transporters, defects of apoptosis and autophagy machinery, alterations of drug metabolism and drug targets, etc., have been identified but their mode of actions is not yet clear. ${ }^{13}$ Due to the limitations in the known cancer treatments, researchers are now working on new methods to overcome multidrug resistance. ${ }^{16,19}$

\section{Multidrug resistance in cancer}

Multidrug resistance (MDR) is a phenomenon characterized by the ability of cancer cells to confer resistance or to become tolerant to antitumor drugs using several mechanisms. ${ }^{6,17,18}$ MDR was first observed in bacteria as they became resistant to some antibiotics, but it has been seen in some other cases and also cancer. ${ }^{20}$ This resistance can either be natural (intrinsic) if tumors become insensitive to therapeutic agents before the commencement of treatment or acquired when tumor becomes resistant during the course of the treatment. ${ }^{21,22}$ Chemotherapy is one of most important treatments for various cancer entities.

Multidrug resistance in cancer has been attributed to the expression of transporters that eject drugs from cells (drug efflux) reducing the efficacy of the drugs. ${ }^{18}$ Other mechanisms involved in multidrug resistance may include: deregulation of cell death mechanisms, modification of drug targets, damaged DNA repair, decreased intracellular accumulation of anticancer drugs, etc. ${ }^{16}$

\section{Mechanisms of multidrug resistance}

The identified mechanisms of multidrug resistance in cancer can act on their own or by combining with different signal transduction pathways. Some of these mechanisms include:

\section{Drug efflux through $A B C$ transporters}

One of the largest known protein families is the $\mathrm{ABC}$ transporters. These transporters contain several groups of active membrane transporters with special functions. The human $\mathrm{ABC}$ protein family has $49 \mathrm{ABC}$ proteins which are divided into seven subfamilies from $\mathrm{ABCA}$ to $\mathrm{ABCG} .^{23}$ The transporters on the plasma membrane major in the influx and efflux of drugs, and they are associated with drug resistance. ${ }^{24}$ These groups of protein families have the ability to reduce the amount of drug that reaches the drug target by pumping out the anticancer drugs out of cancer cells after administration of drugs thereby leading to multidrug resistance..$^{25}$ Determination of drug resistance is made possible by these transporters as they regulate the absorption of drugs, their distribution, metabolism and their elimination (ADME). The $\mathrm{ABC}$ transporters also limit membrane permeability through the blood-tissue barrier (BTB) and blood-brain barrier (BBB), especially ABCB1 (ATP-binding cassette subfamily B member 1, which is also referred to as P-glycoprotein; P-gp), ABCC1 (that is multidrug resistance associated protein 1) and ABDG2 (that 
is breast cancer resistance protein). ${ }^{26,27}$ Overexpression of these transporters are involved in MDR in different types of cancer. The overexpression of $\mathrm{ABCB} 1$ confers $\mathrm{MDR}$ to some anticancer drugs, including paclitaxel, etoposide, teniposide, doxorubicin, actinomycin $\mathrm{D}$, sunitinib, and tacrolimus. ${ }^{28}$

As it has been shown that overexpression of $\mathrm{ABC}$ transporters leads to efflux of chemotherapeutic drugs, therefore, inhibiting these transporters is a means to overcome drug resistance. Modulators that can inhibit these transporters are being designed, enabling antitumor drugs to reach the drug targets. ${ }^{29} \mathrm{Chemosensitizers} \mathrm{such} \mathrm{as} \mathrm{cyclosporine}$ $\mathrm{A}$ and tariquidar, which are $\mathrm{ABCB} 1$ and $\mathrm{ABCC} 1$ inhibitors were tested in clinical trials. ${ }^{30}$ However, their ability to overcome drug resistance in cancer treatment is yet limited. ${ }^{29,31}$ Recently, new methods are being developed to limit the overexpression of $\mathrm{ABC}$ transporters, some of which include drug delivery systems, siRNAs and microRNAs delivered by nanoparticles, and so on (Figure 1). ${ }^{25,30,32}$

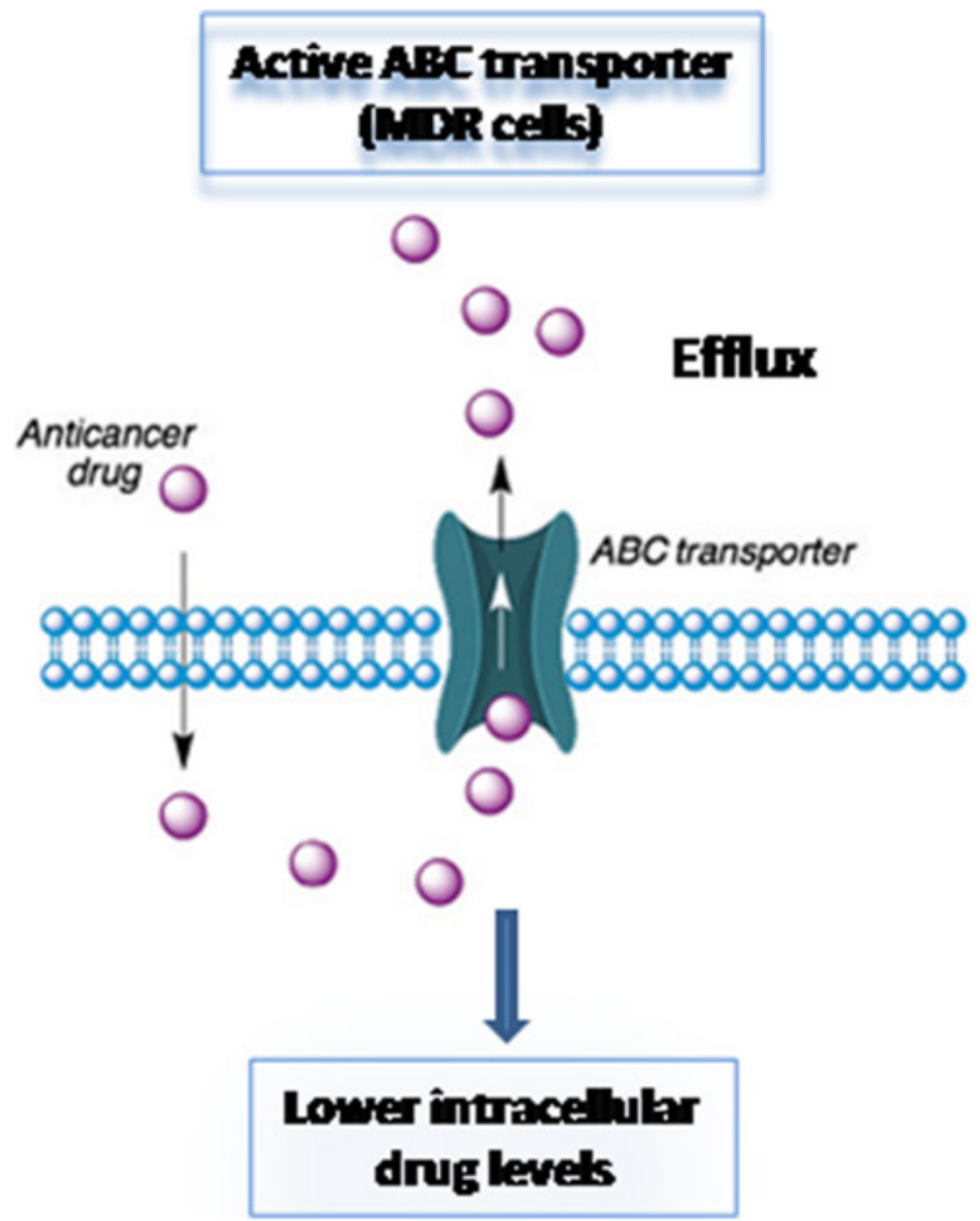

Figure I Schematic representation of MDR in cancer cells with ABC transporter-mediated drug efflux..$^{6,33}$

\section{Deregulation of cell death mechanisms}

The effectiveness of anticancer drugs majors on their ability to cause cell death. Anticancer drugs can cause cell death by inducing reactive oxygen species (ROS), DNA damage and activation of proapoptotic receptors. ${ }^{34,35}$ A major challenge to this is the ability of cancer cells to constantly evolve which enables them to escape cell death. ${ }^{36}$ Cell death mechanisms include apoptosis, necrosis, and autophagy. ${ }^{37}$

a. Apoptotic evasion: Apoptosis, a form of programmed cell death, is the major type of cell death initiated by chemotherapeutic drugs. Apoptosis involves the cleavage of cytoskeletal proteins by caspases (a group of proteases that mediate apoptosis), which initiates the destruction of subcellular components. ${ }^{18}$ Activation of caspases is mediated by death receptor pathways, which are activated when members of the tumor necrosis factor (TNF) super family bind to cell-surface death receptors. ${ }^{37}$ The two established apoptotic pathways are: the intrinsic(mitochondrial) pathway which is controlled by the interaction between members of BCL-2 family and the extrinsic transmembrane pathway. ${ }^{13}$ Survival of cancer cells is usually dependent on anti-apoptotic proteins, such as BCL-2 family members. ${ }^{10,34}$ Overexpression of anti-apoptotic proteins, such as BCL-2, BCL-XL, and MCL-1, initiates drug resistance in cancer cells. ${ }^{38}$ 
As earlier stated, anticancer drugs initiate cell death by increasing the levels reactive oxygen species. Glutathione $(\mathrm{GSH})$ is a major cellular antioxidant defense system and is involved in several metabolic processes. The overexpression of GSH leads to drug resistance by decreasing reactive oxygen species levels, this prevents DNA damage and enhances DNA repair. ${ }^{35,39}$ It was reported by Staudigl et al..$^{40}$ that high $\gamma$ - glutamyltransferase (one of the enzyme that metabolizes glutathione) levels were correlated with therapy resistance in patients with breast cancer. Glutathione S-transferases (GST), a super family of enzymes that conjugates GSH to chemical toxins, is another example. These enzymes help to repress oxidative stress in the human body. It has been shown that overexpression of GST influences cancer survival. ${ }^{41-46}$

b. Induction of Autophagy: Autophagy is an essential biological process involved in maintaining metabolic equilibrium. It is a detox process the body undergoes to clean out damaged cells and regenerate healthier ones. Garcia-Mayea et al.$^{47}$ reported that autophagy promotes tumor in cancer patients. Autophagy enables cancer cells elude apoptosis, this leads to multidrug resistance. ${ }^{13}$ It aids the removal of damaged proteins from cancer cells, this enables cancer cells to survive chemotherapy. Autophagy is an important resistance mechanism activated by CSCs to increase their resistance to drugs. CSCs can however be reduced by autophagy inhibitors that decrease the stemness properties. It was demonstrated that inhibiting autophagy is helpful in reducing cells that poses resistance to chemotherapeutics, including cancer stem cells. ${ }^{47}$

\section{DNA damage repair}

Cancer stem cells (CSCs) have a unique ability to repair DNA damage, this enables them to preserve their DNA. This DNA damage repair mechanism enhances multidrug resistance in cancer cells. $^{48,49}$ Repair mechanisms used may include nucleotide excision repair (NER), mismatch repair (MMR),base excision repair (BER) and double-strand break (DSB). ${ }^{47}$ Dysregulation of these repair systems may be involved in multidrug resistance in cancer cells. ${ }^{50}$ Bonannoet al..$^{51}$ reported that chemotherapeutics containing platinum e.g. cisplatin, cause harmful DNA cross links and lead to apoptosis. However, nucleotide excision repair and homologous recombination which are the primary DNA repair mechanisms involved in reversing platinum damage enable cancer cells develop resistance to drugs containing platinum. ${ }^{20,51}$ Thus, the effectiveness of anticancer drugs depends on the inability of cancer cells to repair DNA damage caused by these chemotherapeutics. The efficacy of the therapy could therefore be increased by inhibiting of repair pathways.

\section{Possible ways out}

Some of the means to overcome the tolerance of cancer cells to anticancer therapy include:

\section{Dysregulation of MicroRNA}

MicroRNAs (miRNAs) are small non-coding RNAs that regulates a large variety of target genes and expression of proteins at a posttranscriptional level. They are about 20-25 nucleotides long. They down-regulate gene expression at a post-transcriptional level, but may sometimes can activate mRNA translation..$^{52}$ Peng \& Croce $^{53}$ reported that microRNAs are involved in cancer development, metastasis and multidrug resistance. MicroRNAs have the ability to influence most mechanisms of drug resistance. They modulate chemotherapeutic drug resistance by the regulation of $\mathrm{ABC}$ membrane transporters.
It was reported by Zhao et al. ${ }^{54}$ that $\mathrm{ABCB} 1$ (P-glycoprotein) is down-regulated significantly by the up-regulation of miR-138. BCL-2 is an essential anti-apoptosis protein and it is targeted by some miRNAs while regulating drug resistance. An et al. ${ }^{13}$ reported thatmiR-30a suppresses stress-induced autophagy by inhibiting the expression of beclin, an important protein in autophagy. ${ }^{55}$ Chronic myelogenous leukemia (CML) cells are sensitized to anti-cancer drugs (e.g. imatinib) by up regulating miR-30a. Another means by which miRNAs influence the sensitivity of cancer cells to anticancer drugs is by altering DNA repair pathways, disenabling DNA damage repair (DDR) mechanisms in cancer cells. MiR-182 was reported to down-regulate the expression of Breast cancer type 1(BRCA1) in breast cancer. Ashomologous recombination-mediated DNA repair was impaired, this increased the sensitivity of tumor cells to anticancer drugs such as poly (ADP-ribose) polymerase(PARP) 1 inhibitor. ${ }^{56}$ According to a study by Sun et al. ${ }^{57}$ miR-9 could downregulate BRCA1 and hinder DNA damage repair in ovarian cancer. This enables cancer cells to be sensitive to anticancer drugs such as cisplatin and inhibitors of Poly (ADP-ribose) polymerase (PARP). ${ }^{13}$

\section{Inhibition of the ABC transporters}

$\mathrm{ABC}$ transporters are reported to be linked up with the level of chemotherapy and the progression of drug resistance. ${ }^{23,58-62}$ The overexpression of ABCB1 (P-gp) contributes greatly to drug resistance in cancer cells. P-gp was reported to reduce the efficacy of its substrate drugs by transporting drugs directly out of cancer cells. ${ }^{27}$ To counter this challenge, efflux function of $\mathrm{ABC}$ transporters can be inhibited, thereby reversing drug resistance in cancer cells. ${ }^{23}$

Midostaurin is a multi-targeted protein kinase inhibitor that has been investigated for the treatment of acute myeloid leukemia (AML). Hsiao et al. ${ }^{27}$ revealed that midostaurin has been approved recently by the Food and Drug Agency (FDA) and the European Medicines Agency(EMA) for the treatment of adult patients with newly diagnosed fms like tyrosine kinase-3 (FLT3)-mutated AML. It inhibits the transport and drug efflux function of ABCB1 (P-gp) selectively. This enables ABCB1-overexpressing cancer cells to respond to chemotherapeutic drugs, thereby reversing drug resistance. In the treatment of drug resistant cancer cells, it was proposed that midostaurin may be combined with other anticancer drugs for improved efficacy. However, further clinical investigations could be carried out to evaluate its efficacy. Also, tepotinibisan anticancer drug undergoing phase 2 clinical trials. Wu et al. ${ }^{63}$ reported that tepotinib reverses the effect on $\mathrm{ABCB} 1$-mediated drug resistance by interacting with the drug-binding domain of ABCB1. Another example is selonsertib that inhibits Apoptosis signal-regulating kinase 1 (ASK1 is involved in certain diseases, including cancer) selectively, hence, overcoming multidrug resistance in cancer. It interacts with the substrate-binding sites of both $\mathrm{ABCB} 1$ and $\mathrm{ABCG} 2$. Combining selonsertib with other anticancer drugs could be a way to overcome multidrug resistance in cancer.

\section{Bioconjugation therapy}

As tumor cells now confer resistance against certain cancer treatments, making them ineffective in cancer treatment, researchers have conjugated drugs with different molecules and delivery vectors to combat such problems and enhance the therapeutic effect anticancer drugs. This is referred to as bioconjugation therapy. Bioconjugates are the new therapeutic strategies, they have the ability to combat the complications being produced by chemotherapeutics. ${ }^{8}$ This technique involves delivering drugs via nanocarriersin which the drug associated 
with the cancer is targeted into the cancer sites. Bioconjugation consists of linking two molecules, usually through a covalent bond, and at least one molecule should be of biological origin. ${ }^{64}$ Alternatively, they can be peptides ${ }^{65,66}$ glycoproteins,${ }^{67}$ aptamers ${ }^{68,69}$ or interferons,${ }^{70}$ etc.; all these have anticancer properties. Bioconjugates are able to target pathological sites and deliver therapeutics to the targeted sites. They also increase the bioavailability of the therapeutics. ${ }^{71}$ Various bioconjugates are linked by chemical functional groups (Figure 2).

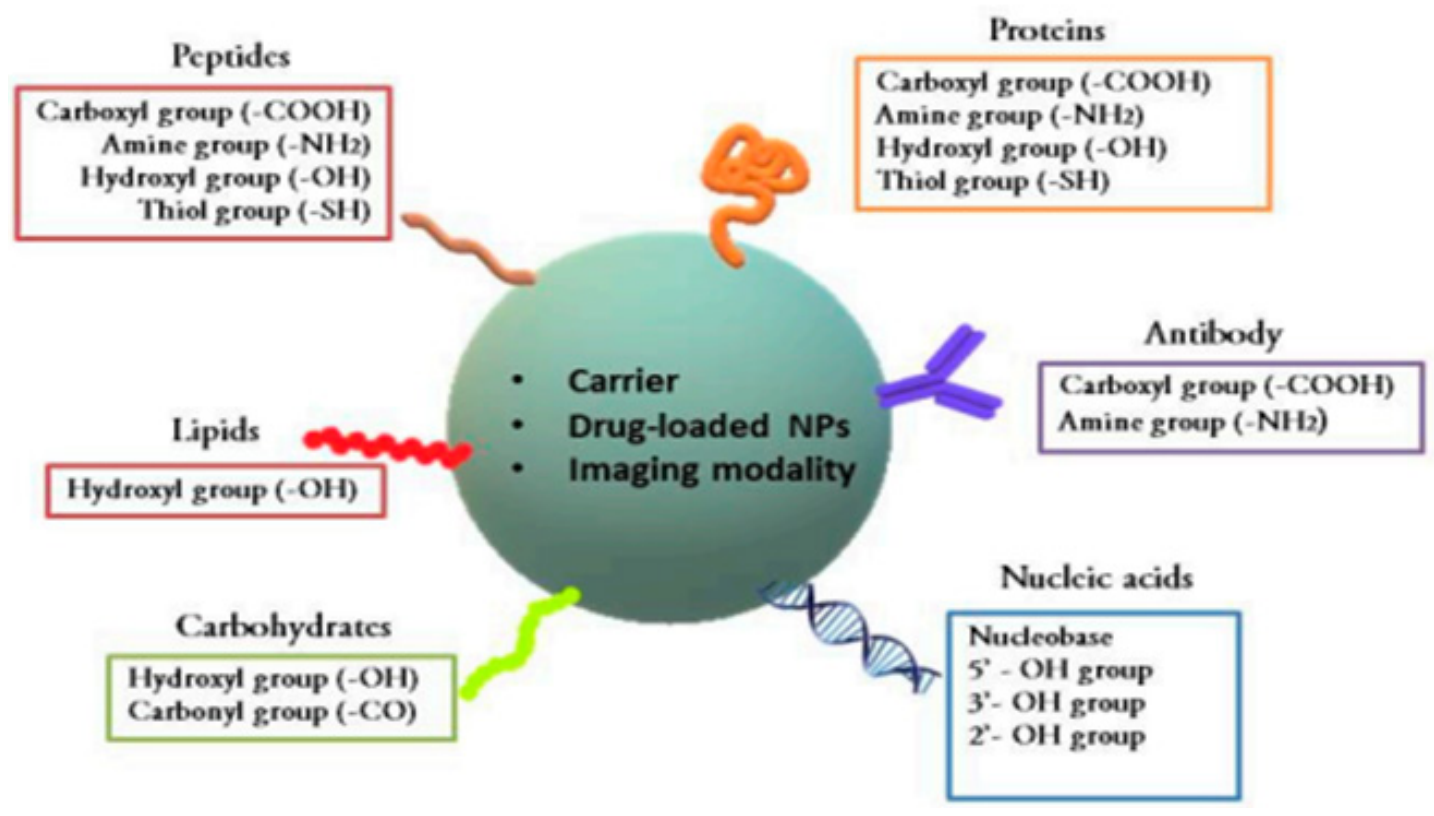

Figure 2 Chemical linkages in bioconjugates. Nanoparticles are abbreviated as NPs. ${ }^{8}$

Silencing RNA (siRNA) therapy is another measure for cancer treatment. This involves linking antibodies and ligands chemically with siRNA nanoparticles. It is referred to assiRNA-mediated silencing (RNAi) of genes. Oncogenes are genes that has the potential to cause cancer, they are usually mutated or overexpressed in cancer cells. They lead to tumor proliferation, metastasis, angiogenesis, and multidrug resistance. Silencing RNAs target oncogenes and inhibit apoptosis. ${ }^{72}$ A major problem to the use of bioconjugates is its production cost which is quite expensive, making it unsustainable in underdeveloped and developing countries, especially to the lessprivileged. ${ }^{8}$

\section{Treatment with natural products}

A large variety of chemical substances with great importance and usefulness are found in nature. Natural products are molecules with several usefulness, some of them serve as alternatives to synthetic compounds for the development as chemosensitizers. They are combined with chemotherapeutic agents to enhance their efficacy in cancer cells. Synthetic multidrug resistance drugs are limited in treating cancer patients. Current researches have focused on beneficial effects of compounds from natural sources. Several phenolcontaining compounds (such as flavones, phenolcarboxylic acids, ellagitannins, stilbens, lignans, curcumin, etc.) and phytochemicals act as chemopreventive agents. They possess antioxidant activity, they inhibit of proliferation, survival and metastasis, and they also modulate immune and inflammatory responses. ${ }^{6}$

Curcumin, an active constituent of turmeric, is one of the natural products with unique biological activities. It can prevent the initiation of cancer, repress proliferation, and initiates apoptosis in cancer cells. Combining curcumin with other anticancer drugs may sensitize cancer cells to anticancer drugs, this could help to overcome drug resistance in cancer treatment. However, curcumin has been limited in its antitumor function due to its instability and rapid metabolism. In a study by Lopes-Rodrigues and colleagues a small library of new curcumin derivatives were screened for anticancer and ABCB1 regulatory activities. One of the newly synthesized derivatives of curcumin was shown to possess more potent anticancer activity and also has the ability to modulate the function of $\mathrm{ABCB} 1$ than curcumin.

Caffeic acid is a non-flavonoid phenolic acid commonly found in vegetables and fruits. It is an antioxidant of biological origin. Due to its antioxidant properties, it has been shown to have anti-inflammatory properties. Teng and co-workers revealed in their study that caffeic acid counters multidrug resistance in cancer. It performs this function by inhibiting the efflux function of human $\mathrm{ABCB} 1$ and retains anticancer drugs inside the cancer cells, thus cell death is promoted. Asides this phenolic acid, caffeic acid phenethyl ester (CAPE), a derivative of caffeic acid, possesses some therapeutic effects in the treatment of cancer.

Steroids are used as anti-swelling agent in cancer treatment, ${ }^{73}$ $\beta$-Sitosterol (a plant-based sterol) also possess anticancer activity. Andima et al. ${ }^{74}$ encapsulated this phytosterol into poly (lactide-coglycolic acid) (PLGA) and poly (ethylene glycol)-block-poly (lactic acid) nanoparticles. This increased the solubility and therapeutic efficacy of the plant-based sterol against breast cancer.

Previous studies revealed that vitamin D (a fat-soluble vitamin) may inhibit oncogenesis or tumorigenesis and slows down tumor progression. It has anti-inflammatory, immunomodulatory, proapoptotic, and antiangiogenic properties and may decrease death rate from cancer. ${ }^{75-77}$ It was reported that cancer patients with higher 25-hydroxyvitamin D levels might live longer. ${ }^{78}$ It was also shown by Chang et al. ${ }^{79}$ that tenulin (a major sesquiterpene lactone component 
isolated from Helenium amarum) and isotenulin inhibit the drug efflux function of ABCB1 via inhibition mechanisms through ATPase stimulation. These compounds also restored the sensitivity of cancer cells to chemotherapeutic drugs. ${ }^{80-108}$

\section{Acknowledgments}

Nil.

\section{Conflicts of interest}

The authors declare that they have no competing interests.

\section{Funding}

No funding source supported this study.

\section{References}

1. Stewart BW, Wild CP. World Cancer Report 2014 . BW Stewart, CP wild, world Cancer report 2014. Lyon: International Agency for Research Cancer; 2014.

2. Si W, Shen J, Zheng H, et al. The role and mechanisms of action of microRNAs in cancer drug resistance. Clin Epigenetics. 2019;11(1):25.

3. Boveri T. Concerning the origin of malignant tumours by Theodor Boveri. Translated and an notated by Henry Harris. J Cell Sci. 2008;121Suppl $1: 1-84$.

4. Yousafzai NA, Wang H, Wang Z, et al. Exosome mediated multidrug resistance in cancer. Am J Cancer Res. 2018;8(11):2210-2226.

5. Mbaveng AT, Kuete V, Efferth T. Potential of central, eastern and western Africa medicinal plants for cancer therapy: spotlight on resistant cells and molecular targets. Front Pharmacol. 2017;8:343.

6. Hamed AR, Abdel-Azim NS, Shams KA, et al. Targeting multidrug resistance in cancer by natural chemosensitizers. Bulletin of the National Research Centre. 2019;43(1):8.

7. Balkwill F, Berlato C, Fletcher L. U.S. Patent Application No. 10/241,118. 2019.

8. Wadhawan A, Chatterjee M, Singh G. Present Scenario of Bioconjugates in Cancer Therapy: A Review. Int J Mol Sci. 2019;20(21):5243.

9. Bray F, Ferlay J, Soerjomataram I, et al. Global cancer statistics 2018: GLOBOCAN estimates of incidence and mortality worldwide for 36 cancers in 185 countries. CA Cancer J Clin. 2018;68(6):394-424.

10. Holohan C, Van Schaeybroeck S, Longley DB, et al. Cancer drug resistance: an evolving paradigm. Nat Rev Cancer. 2013;13(10):714-726.

11. Sun Y, Campisi J, Higano C, et al. Treatment-induced damage to the tumor microenvironment promotes prostate cancer therapy resistance through WNT16B. Nat Med. 2012;18(9):1359-1368.

12. Szakács G, Paterson JK, Ludwig JA, et al. Targeting multidrug resistance in cancer. Nat Rev Drug Discov. 2006;5(3):219-234.

13. An X, Sarmiento C, Tan T, et al. Regulation of multidrug resistance by microRNAs in anti-cancer therapy. Acta pharm $\sin$ B. 2017;7(1):38-51.

14. Wang H, Gao Z, Liu X, et al. Targeted production of reactive oxygen species in mitochondria to overcome cancer drug resistance. Nat commun. 2018;9(1):562.

15. Broxterman HJ, Gotink KJ, Verheul HMW. Understanding the causes of multidrug resistance in cancer: a comparison of doxorubicin and sunitinib. Drug Resist Updat. 2009;12(4-5):114-126.

16. Corrà $\mathrm{F}$, Agnoletto $\mathrm{C}$, Minotti L, et al. The network of non-coding RNAs in cancer drug resistance. Front oncol. 2018;8:327.
17. Gottesman MM. Mechanisms of cancer drug resistance. Аnпи Rev Med. 2002;53:615-627.

18. Assaraf YG, Brozovic A, Gonçalves AC, et al. The multi-factorial nature of clinical multidrug resistance in cancer. Drug Resist Updat. 2019;46:100645.

19. Giovannetti E, Erozenci A, Smit J, et al. Molecular mechanisms underlying the role of microRNAs (miRNAs) in anticancer drug resistance and implications for clinical practice. Crit Rev Oncol Hematol. 2012;81(2):103-122.

20. Housman G, Byler S, Heerboth S, et al. Drug resistance in cancer: an overview. Cancers. 2014;6(3):1769-1792.

21. Gong J, Jaiswal R, Mathys JM, et al. Microparticles and their emerging role in cancer multidrug resistance. Cancer Treat Rev. 2012;38(3):226234.

22. Baguley BC. Multidrug resistance in cancer. Methods Mol Biol. 2010;596:1-14

23. Ji N, Yang Y, Cai CY, et al. Selonsertib (GS-4997), an ASK1 inhibitor, antagonizes multidrug resistance in $\mathrm{ABCB} 1$-and $\mathrm{ABCG}$-overexpressing cancer cells. Cancer lett. 2019;440:82-93.

24. Yardley DA. Drug resistance and the role of combination chemotherapy in improving patient outcomes. Int J Breast Cancer. 2013:137414.

25. Li W, Zhang H, Assaraf YG, et al. Overcoming ABC transporter-mediated multidrug resistance: molecular mechanisms and novel therapeutic drug strategies. Drug Resist Updat. 2016;27:14-29.

26. Bruhn O, Cascorbi I. Polymorphisms of the drug transporters ABCB1, $\mathrm{ABCG} 2, \mathrm{ABCC} 2$ and $\mathrm{ABCC} 3$ and their impact on drug bioavailability and clinical relevance. Expert Opin Drug Metab Toxicol. 2014;10(10):13371354 .

27. Hsiao SH, Lusvarghi S, Huang YH, et al. The FLT3 inhibitor midostaurin selectively resensitizes $\mathrm{ABCB} 1$-overexpressing multidrug-resistant cancer cells to conventional chemotherapeutic agents. Cancer lett. 2019;445:34-44.

28. Sodani K, Patel A, Kathawala RJ, et al. Multidrug resistance associated proteins in multidrug resistance. Chin J Cancer. 2012;31(2):58-72.

29. Kathawala RJ, Gupta P, Ashby Jr CR, et al. The modulation of ABC transporter-mediated multidrug resistance in cancer: a review of the past decade. Drug Resist Updat. 2015;18:1-17.

30. Jaramillo AC, Al Saig F, Cloos J, et al. How to overcome ATP-binding cassette drug efflux transporter-mediated drug resistance. Cancer Drug Resist. 2018;1:6-29.

31. Palmeira A, Sousa E, Vasconcelos H, et al. Three decades of P-gp inhibitors: skimming through several generations and scaffolds. Curr Med Chem. 2012;19(13):1946-2025.

32. Bar-Zeev M, Livney, YD, Assaraf YG. Targeted nanomedicine for cancer therapeutics: Towards precision medicine overcoming drug resistance. Drug Resist Updat. 2017;31:15-30.

33. Avendaño C, Menéndez JC. Chapter 14-drugs that modulate resistance to antitumor agents. In: Medicinal chemistry of anticancer drugs. Boston: Elsevier; 2015:655-700.

34. Tarasov VV, Chubarev VN, Ashraf GM, et al. How Cancer Cells Resist Chemotherapy: Design and Development of Drugs Targeting ProteinProtein Interactions. Curr Top Med Chem. 2019;19(6):394-412.

35. Yang H, Villani RM, Wang H, et al. The role of cellular reactive oxygen species in cancer chemotherapy. J Exp Clin Cancer Res. 2018;37(1):266.

36. Indran IR, Tufo G, Pervaiz S, et al. Recent advances in apoptosis, mitochondria and drug resistance in cancer cells. Biochim Biophys Acta. 2011:1807(6):735-745. 
37. Green DR, Llambi F. Cell death signaling. Cold Spring Harb Perspect Biol. 2015;7(12):a006080.

38. Zheng HC. The molecular mechanisms of chemoresistance in cancers. Oncotarget. 2017;8(35):59950-599564.

39. Traverso N, Ricciarelli R, Nitti M, et al. Role of glutathione in cancer progression and chemoresistance. Oxid Med Cell Longev. 2013;2013:972913

40. Staudigl C, Concin N, Grimm C, et al. Prognostic relevance of pretherapeutic gamma-glutamyltransferase in patients with primary metastatic breast cancer. PloS one. 2015;10(4):e0125317.

41. Schnekenburger M, Karius T, Diederich M. Regulation of epigenetic traits of the glutathione S-transferase P1 gene: from detoxification toward cancer prevention and diagnosis. Front Pharmacol. 2014;5:170.

42. Jardim BV, Moschetta MG, Leonel C, et al. Glutathione and glutathione peroxidase expression in breast cancer: An immunohistochemical and molecular study. Oncol Rep. 2013;30(3):1119-1128.

43. Backos DS, Franklin CC, Reigan P. The role of glutathione in brain tumor drug resistance. Biochem pharmacol. 2012;83(8):1005-1012.

44. Singh S. Cytoprotective and regulatory functions of glutathione S-transferases in cancer cell proliferation and cell death. Cancer chemother pharmacol. 2015;75(1):1-15.

45. Ge J, Tian AX, Wang QS, et al. The GSTP1 105Val allele increases breast cancer risk and aggressiveness but enhances response to cyclophosphamide chemotherapy in North China. PloS one. 2013;8(6):e67589.

46. Kap EJ, Richter S, Rudolph A, et al. Genetic variants in the glutathione S-transferase genes and survival in colorectal cancer patients after chemotherapy and differences according to treatment with oxaliplatin. Pharmacogenet Genomics. 2014;24(7):340-347.

47. Garcia-Mayea Y, Mir C, Masson F, et al. Insights into new mechanisms and models of cancer stem cell multidrug resistance. Semin Cancer Biol. 2020;60:166-180.

48. Skvortsov S, Debbage P, Lukas P, et al. Crosstalk between DNA repair and cancer stem cell (CSC) associated intracellular pathways. Semin Cancer Biol. 2015;31:36-42.

49. Carruthers RD,Ahmed SU, Ramachandran S, et al. Replication stress drives constitutive activation of the DNA damage response and radioresistance in glioblastoma stem-like cells. Cancer Res. 2018;78(17):5060-5071.

50. Cuestas ML, Castillo AI, Sosnik A, et al. Downregulation of mdrl and abcg2 genes is a mechanism of inhibition of efflux pumps mediated by polymeric amphiphiles. Bioorg Med Chem Lett. 2012;22(21):6577-6579.

51. Bonanno L, Favaretto A, Rosell R. Platinum drugs and DNA repair mechanism in lung cancer. Anticancer Res. 2014;34(1):493-502.

52. Gebert LF, MacRae IJ. Regulation of microRNA function in animals. Nat Rev Mol Cell Biol. 2019;20(1):21-37.

53. Peng Y, Croce CM. The role of MicroRNAs in human cancer. Signal Transduct Target Ther. 2016;1:15004.

54. Zhao X, Yang L, Hu J, et al. miR-138 might reverse multidrug resistance of leukemia cells. Leuk Res. 2010;34(8):1078-1082.

55. Zhu H, Wu H, Liu X, et al. Regulation of autophagy by a beclin 1-targeted microRNA, miR-30a, in cancer cells. Autophagy. 2009;5(6):816-823.

56. Moskwa P, Buffa FM, Pan Y, et al. miR-182-mediated downregulation of BRCA1 impacts DNA repair and sensitivity to PARP inhibitors. Mol cell. 2011;41(2):210-220

57. Sun C, Li N, Yang Z, et al. miR-9 regulation of BRCA1 and ovarian cancer sensitivity to cisplatin and PARP inhibition. $J$ Natl Cancer Inst. 2013;105(22):1750-1758
58. Liu YS, Hsu HC, Tseng KC, et al. Lgr5 promotes cancer stemness and confers chemoresistance through ABCB1 in colorectal cancer. Biomed Pharmacother. 2013;67(8):791-799.

59. Ali MA, Elsalakawy WA. ABCB1 haplotypes but not individual SNPs predict for optimal response/failure in Egyptian patients with chronicphase chronic myeloid leukemia receiving imatinib mesylate. Med Oncol. 2014;31(11):279.

60. Xie ZY, Lv K, Xiong Y, et al. ABCG2-meditated multidrug resistance and tumor-initiating capacity of side population cells from colon cancer. Oncol Res Treat. 2014;37(11):670-672.

61. Liu L, Zuo, LF, Guo JW. ABCG2 gene amplification and expression in esophageal cancer cells with acquired adriamycin resistance. Mol Med Rep. 2014;9(4):1299-1304.

62. Yang B, Ma YF, Liu Y. Elevated expression of Nrf-2 and ABCG2 involved in multi-drug resistance of lung cancer SP cells. Drug res. 2015;65(10):526-531

63. Wu ZX, Teng QX, Cai CY, et al. Tepotinib reverses ABCB1-mediated multidrug resistance in cancer cells. Biochem Pharmacol. 2019;166:120127.

64. Hermanson GT. Chapter 1-Introduction to bioconjugation. Bioconjugate Techniques. 3rd ed. Boston, MA: Academic Press; 2013:1-125.

65. Kumar M, Gupta D, Singh G, et al. Novel polymeric nanoparticles for intracellular delivery of peptide cargos: antitumor efficacy of the BCL-2 conversion peptide NuBCP-9. Cancer Res. 74(12):3271-3281.

66. Szweda R, Trzebicka B, Dworak A, et al. Smart polymeric nanocarriers of Met-enkephalin. Biomacromolecules. 2016;17(8):2691-2700.

67. Casañas Pimentel RG, Robles Botero V, San Martín Martínez E, et al. Soybean agglutinin-conjugated silver nanoparticles nanocarriers in the treatment of breast cancer cells. J Biomater Sci Polym Ed. 2016;27(3):218-234.

68. Perepelyuk M, Maher C, Lakshmikuttyamma A, et al. Aptamer-hybrid nanoparticle bioconjugate efficiently delivers miRNA-29b to non-smallcell lung cancer cells and inhibits growth by downregulating essential oncoproteins. Int J Nanomedicine. 2016;11:3533-3544.

69. Tao W, Zeng X, Wu J, et al. Polydopamine-based surface modification of novel nanoparticle-aptamer bioconjugates for in vivo breast cancer targeting and enhanced therapeutic effects. Theranostics. 2016;6(4):470484 .

70. Montagner IM, Merlo A, Carpanese D, et al. A site-selective hyaluronaninterferon $\alpha 2$ a conjugate for the treatment of ovarian cancer. $J$ Control Release. 2016;236:79-89.

71. Sun X, Zhang G, Patel D, et al. Targeted cancer therapy by immunoconjugated gold-gold sulfide nanoparticles using Protein $\mathrm{G}$ as a cofactor. Ann Biomed Eng. 2012;40(10):2131-2139.

72. Tietze S, Schau I, Michen S, et al. A poly (propyleneimine) dendrimerbased polyplex-system for single-chain antibody-mediated targeted delivery and cellular uptake of SiRNA. Small. 2017;13(27):1700072.

73. Lossignol D. A little help from steroids in oncology. J Transl Int Med. 2016;4(1):52-54.

74. Andima M, Costabile G, Isert L, et al. Evaluation of $\beta$-Sitosterol Loaded PLGA and PEG-PLA Nanoparticles for Effective Treatment of Breast Cancer: Preparation, Physicochemical Characterization, and Antitumor Activity. Pharmaceutics. 2018;10(4):232.

75. Del Valle HB, Yaktine AL, Taylor CL, et al. Dietary reference intakes for calcium and vitamin D. National Academies Press. 2011.

76. Feldman D, Krishnan AV, Swami S, et al. The role of vitamin D in reducing cancer risk and progression. Nat Rev Cancer. 2014;14(5):342-357. 
77. Manson JE, Cook NR, Lee IM, et al. Vitamin D supplements and prevention of cancer and cardiovascular disease. N Engl J Med. 2019;380(1):33-44.

78. Keum N, Giovannucci E. Vitamin D supplements and cancer incidence and mortality: a meta-analysis. Br J Cancer. 2014;111(5):976-980.

79. Chang YT, Wang CC, Wang JY, et al. Tenulin and isotenulin inhibit P-glycoprotein function and overcome multidrug resistance in cancer cells. Phytomedicine. 2019;53:252-262.

80. All Cancers Fact Sheet, GLOBOCAN 2018. The Global Cancer Observatory.

81. Bauer SR, Hankinson SE, Bertone-Johnson ER, et al. Plasma vitamin D levels, menopause, and risk of breast cancer: dose-response meta-analysis of prospective studies. Medicine. 2013;92(3):123-131.

82. Fujisawa T. Therapeutic application of apoptosis signal-regulating kinase 1 inhibitors. Adv Biol Regul. 2017;66:85-90.

83. Gioeli D. Targeted Therapies. Mechanisms of Resistance. New York: Humana Press. 2011:202.

84. Gottesman MM, Pastan IH. The role of multidrug resistance efflux pumps in cancer: revisiting a JNCI publication exploring expression of the MDR1 (P-glycoprotein) gene. J Natl Cancer Inst. 2015;107(9):djv222.

85. Hayakawa R, Hayakawa T, Takeda K. et al. Therapeutic targets in the ASK1-dependent stress signaling pathways. Proc Jpn Acad Ser B Phys Biol Sci. 2012;88(8):434-453.

86. Marin JG, Briz O, Monte MJ, et al. Genetic variants in genes involved in mechanisms of chemoresistance to anticancer drugs. Curr Cancer Drug Targets. 2012;12(4):402-438.

87. Kim SW, Kwon HY, Chi DW, et al. Reversal of P-glycoproteinmediated multidrug resistance by ginsenoside Rg3. Biochem Pharmacol. 2003;65(1):75-82.

88. Lemos C, Jansen G, Peters GJ. Drug transporters: recent advances concerning BCRP and tyrosine kinase inhibitors. $\mathrm{Br} J$ Cancer. 2008;98(5):857-862.

89. Marchetti S, de Vries NA, Buckle T, et al. Effect of the ATP-binding cassette drug transporters $\mathrm{ABCB} 1, \mathrm{ABCG} 2$, and $\mathrm{ABCC} 2$ on erlotinib hydrochloride (Tarceva) disposition in in vitro and in vivo pharmacokinetic studies employing Bcrp1-/-/Mdr1a/1b-/-(triple-knockout) and wildtype mice. Mol Cancer Ther. 2008;7(8):2280-2287.

90. McCullough ML, Zoltick ES, Weinstein SJ, et al. Circulating vitamin D and colorectal cancer risk: an international pooling project of 17 cohorts. J Natl Cancer Inst. 2019;111(2):158-169.

91. Mehta K, Fok JY. Targeting transglutaminase-2 to overcome chemoresistance in cancer cells. In: Mehta K, et al. editors. Drug Resistance in Cancer Cells. New York, NY, USA: Springer; 2009:95-114.

92. Mondul AM, Weinstein SJ, Layne TM, et al. Vitamin D and cancer risk and mortality: state of the science, gaps, and challenges. Epidemiol Rev. 2017;39(1):28-48.
93. Nishida $T$, Hattori $K$, Watanabe $K$. The regulatory and signaling mechanisms of the ASK family. Adv Biol Regul. 2017;66:2-22.

94. Olaussen K, Dunant A, Fouret P, et al. DNA repair by ERCC1 in nonsmall-cell lung cancer and cisplatin-based adjuvant chemotherapy. $N$ Engl J Med. 2006;355(10):983-991.

95. Quester K, Juarez-Moreno K, Secundino I, et al. Cytochrome P450 bioconjugate as a nanovehicle for improved chemotherapy treatment. Macromol Biosci. 2017;17(5).

96. Robey RW, Pluchino KM, Hall MD, et al. Revisiting the role of $\mathrm{ABC}$ transporters in multidrug-resistant cancer. Nat Rev Cancer. 2018;18(7):452-464.

97. Ryuno H, Naguro I, Kamiyama M. ASK family and cancer. Adv Biol Regul. 2017;66:72-84.

98. Safa AR. Resistance to cell death and its modulation in cancer stem cells Crit Rev Oncog. 2016;21(3-4):203-219.

99. Salmaso S, Caliceti P. Peptide and Protein Bioconjugation: A Useful Tool to Improve the Biological Performance of Biotech Drugs. In: Peptide and Protein Delivery. Academic Press. 2011:247-290.

100. Selvakumaran M, Pisarcik D, Bao R, et al. Enhanced cisplatin cytotoxicity by disturbing the nucleotide excision repair pathway in ovarian cancer cell lines. Cancer Res. 2003;63(6):1311-1316.

101. Steeg PS. Targeting metastasis. Nat Rev Cancer. 2016;16(4):201-218.

102. Townsend DM, Tew KD. The role of glutathione-S-transferase in anticancer drug resistance. Oncogene. 2003;22(47):7369-7375.

103. Wang Q, Shu X, Dong Y, et al. Tumor and serum gamma-glutamyl transpeptidase, new prognostic and molecular interpretation of an old biomarker in gastric cancer. Oncotarget. 2017;8(22):36171-36184.

104. Wilson TR, Longley DB, Johnston PG. Chemoresistance in solid tumours. Ann Oncol. 2006;17 Suppl 10:x315-x324.

105. Wong AL, Lee SC. Mechanisms of resistance to trastuzumab and novel therapeutic strategies in HER2-positive breast cancer. Int J Breast Cancer. 2012;2012:415170.

106. Wu CP, Hsiao SH, Su CY, et al. Human ATP-Binding Cassette transporters $\mathrm{ABCB} 1$ and $\mathrm{ABCG} 2$ confer resistance to CUDC-101, a multi-acting inhibitor of histone deacetylase, epidermal growth factor receptor and human epidermal growth factor receptor 2. Biochem Pharmacol. 2014;92(4):567-576.

107. Xia L, Zhang D, Du R, et al. miR-15b and miR-16 modulate multidrug resistance by targeting BCL2 in human gastric cancer cells. Int J Cancer. 2008;123(2):372-379.

108. Yin L, Ordóñez-Mena JM, Chen T, et al. Circulating 25-hydroxyvitamin $\mathrm{D}$ serum concentration and total cancer incidence and mortality: a systematic review and meta-analysis. Prev Med. 2013;57(6):753-764. 